\title{
Sleeve gastrectomy compared to gastric banding in management of morbidly obese patients
}

\author{
Samy Saad, ${ }^{a}$ MD; Alaa El-Ashry, ${ }^{a}$ FRCS; A Meccawy, ${ }^{b}$ FRCS
}

\author{
a) Department of General Surgery, Ain Shams University, Cairo, Egypt. \\ b) Department of General Surgery, King Abdulaziz University Hospital, KSA.
}

\begin{abstract}
Background: The use of bariatric surgery in the management of morbid obesity is rapidly increasing. Two of the most frequently performed procedures are laparoscopic sleeve gastrectomy and laparoscopic gastric banding. The objective of this study is to provide a critical appraisal of the most relevant scientific evidence comparing laparoscopic gastric banding versus laparoscopic sleeve gastrectomy in the treatment of morbidly obese patients.

Materials and methods: The study was done in Bugshan Hospital, King Abdulaziz University Hospital and Prince Abd El Aziz Bin Mosaed Hospital in Saudi Arabia where 100 patients ( 82 females and 18 males ), with ages ranging between 25 and 46 years were operated upon between May 2005 and November 2007. They were randomly assigned into 2 groups: Group 1 : 52 patients (40 females and 10 males) were assigned to laparoscopic adjustable gastric band. Group $2: 48$ patients (42 females and 8 males) were assigned to laparoscopic sleeve gastrectomy.

Results: After 1 year follow up, there was a statistically significant difference between the two groups regarding the mean BMI and the rate of complications $(p<0.05)$. There was a significant difference between both groups $(p<0.05)$ regarding pouch that was reported in 4 patients $(7.6 \%)$ in group 1 and one patient (2.1\%) in group 2. Stable line leak was reported in 2 cases (4.2\%) and band erosion was reported in 2 cases (3.8\%) where re-operation and band removal was done for both of them.

After 3 years follow up, there was a statistically significant difference between the 2 groups regarding the mean BMI ( $p<0.05)$. There was no significant difference between the two groups regarding the rate of complications ( $p>0.05)$. Four patients $(8.3 \%)$ in group 2 acquired pouch dilatation. Re-operation and conversion to Roux-en-Y gastric bypass was done to 2 of them. Herniation at the right hypochondrial port site developed in one patient (2.1\%) in group 2. Insufficient weight loss was present in 2 patients (3.8\%) in group 1 and in 2 patients (4.2\%) in group 2 which was not statistically significant $(p>0.05)$.

Conclusion: Sleeve gastrectomy is significantly more effective than gastric banding in terms of late complications, late reoperations, and long-term results on weight loss.
\end{abstract}

\section{Introduction:}

The prevalence of obesity as well as its associated morbidity and mortality are rising at an alarming rate in industrialized countries. ${ }^{1,3}$ This has a major public health impact as morbid obesity is associated with diabetes, arterial hypertension, hypercholesterolemia, sleep apnea syndrome, arthritis, and decreased life expectancy. Unfortunately, attempts to lose weight with dieting, behavioral modifications, and exercise are unsuccessful in the vast majority of morbidly obese patients. ${ }^{2}$ Therefore, different bariatric surgery procedures have been developed. The introduction of laparoscopic surgery has created a revolution in the field of bariatric surgery 4,6 Laparoscopic procedures have progressively replaced traditional open bariatric procedures in both Europe and North America. Gastric bypass, duodenal switch, and gastric banding are the most commonly performed laparoscopic procedure in USA and Canada ${ }^{4}$ while in Europe, laparoscopic gastric restrictive procedures still represent the majority of 
bariatric procedures. ${ }^{5}$ Laparoscopic adjustable silicone gastric banding (LASGB) was first reported by Morino et al. in $1994 .{ }^{7}$ Introduction of gastric banding into clinical practice was an immediate success. It caused the rapid growth of bariatric programs in surgical departments throughout European countries, where these procedures were limited to a few centers in the past. Vertical banded gastroplasty (VBG) was the most popular gastric restrictive procedure during the pre-laparoscopic era. Gastric banding and sleeve procedure do not differ significantly in many ways as both are exclusively restrictive procedures. Furthermore, the laparoscopic implantation of a gastric band is technically much less challenging, does not have the risk of suture line leak, and can be performed without specific training for laparoscopic and/or bariatric surgery. ${ }^{7}$ Conversely, the laparoscopic sleeve gastrectomy has the risk of suture line leak, and is usually performed by surgeons with advanced laparoscopic or specifically laparoscopic-bariatric surgery training. ${ }^{8}$ The use of laparoscopic gastric banding may seem appealing at first as the rate of early postoperative complications is low and the hospital stay short. 9 However, there have been numerous reports on long-term complications such as band slippage and migration, pouch and esophageal dilation, port-site infection, and failure to lose weight in some cases, all of which frequently require the band removal. 8,16

The objective of this study is to compare laparoscopic gastric banding versus laparoscopic sleeve gastrectomy for patients with morbid obesity.

\section{Materials and methods:}

The study was done in Bugshan Hospital, King Abdulaziz University Hospital and Prince Abd El Aziz Bin Mosaed Hospital in Saudi Arabia where 100 patients ( 82 females and 18 males) were operated upon between May 2005 and November 2007. Their ages ranged between 25 and 46 years. They were randomly assigned into 2 groups:

- Group 1: 52 patients (40 females and 12 males) were assigned to laparoscopic adjustable gastric band.

- Group 2: 48 patients (42 females and 6 males) were assigned to laparoscopic sleeve gastrectomy.

Patients were considered candidates for either operation when their BMI were $>40$ $\mathrm{kg} / \mathrm{m}^{2}$, no history of drug or alcohol intake and all of them had failed at previous restrictive diet measures to lose weight. All patients were nonbinge, nonsweet eaters with no endocrinal cause for their obesity. All patients had an informed consent of the procedure's risk and the chances for conversion to open surgery. Routine laboratory investigations, ECG, chest radiograph and abdominal ultrasonography were done to all patients. If there was an associated gall bladder stones, a cholecystectomy was routinely performed at the time of surgery. Prophylactic antibiotic, $\mathrm{H}_{2}$ blockers and subcutaneous heparin were employed routinely in all patients.

\section{Laparoscopic sleeve gastrectomy}

Under GA, the abdomen was insufflated with $\mathrm{CO}_{2}$ by Veress needle, then four or five trockers were positioned in the anterior abdominal wall into the peritoneal cavity. The gastrocolic ligament was opened as a first step in the operation starting about $5 \mathrm{~cm}$ from the pylorus and divided along the whole greater curvature up to the gastro-esophageal junction freeing the whole gastric greater curvature Figures(1,2). A 34-Fr gastric tube was then inserted inside the stomach up to the pylorus. The stomach was then divided with multiple linear staplers parallel, and adjacent to, the intra-gastric tube along the lesser curvature Figures $(3,4)$. The division line was reinforced with running sutures vicryl $2 / 0$ and a methylene blue test was performed to detect any suture line leak Figure(5). The resected part of the stomach was then extracted out from the peritoneal cavity and the wounds were closed without intra-peritoneal drain Figure(6).

\section{Laparoscopic gastric banding:}

The patient was positioned in the same position as in sleeve gastrectomy. The phrenogastric ligament at the angle of His was dissected and opened Figure(7). The pars flaccida was then opened Figure(8), the right crus was dissected and dissection was progressed bluntly and carefully behind the posterior wall of the gastroesophageal junction up to the angle of His Figures $(\mathbf{9 , 1 0})$. The band was introduced into the abdomen, grasped and pulled gently in the retroesophagogastric space 
Figures(11,12). A gastric tube was inflated up to $15 \mathrm{ml}$. and kept against the cardia to create a $15 \mathrm{ml}$-sized gastric pouch. The band was then encircled around the pouch Figure(13). In all cases, we used the Swedish Adjustable Gastric Band (SAGB) (Obtech, St. Anton, Switzerland). Two ethibond 2/0 seromascular sutures were placed on the ventral side below and above the band overlapping the anterior gastric wall in front of the band to ensure its stable anterior position Figure(14). The reservoir was then fixed deep to the rectus sheath at the left hypochondral port site. The

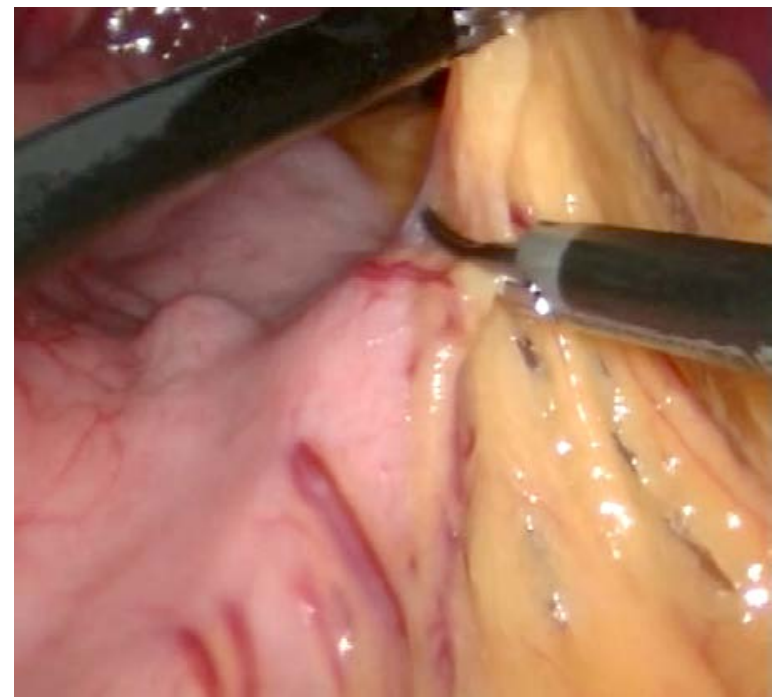

Figure(1): Division of gastrocolic ligament.

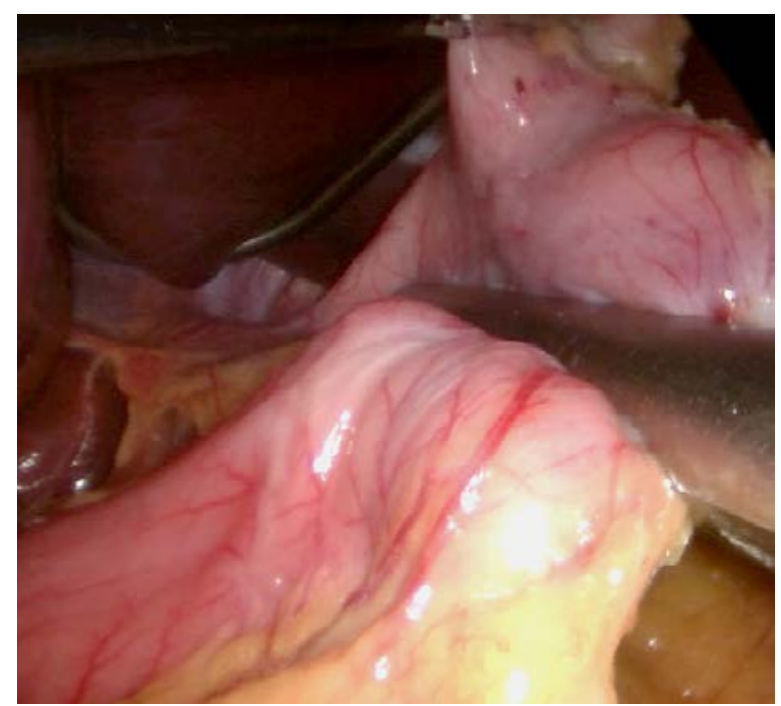

Figure(3): Stomach divided adjacent to the gastric tube. wounds were closed without intra-peritoneal drain. The patients started the first band insufflation session one month later which was repeated monthly for the next 5 to 8 months.

In all cases of the study, antibiotics were continued for 3 days postoperatively, heparin was stopped when the patients were able to leave the bed and $\mathrm{H}_{2}$-blockers were given orally for 1 month. The patients were allowed for oral fluid diet in the first 2 post-operative weeks followed by semisolid oral food in the next 2 weeks.

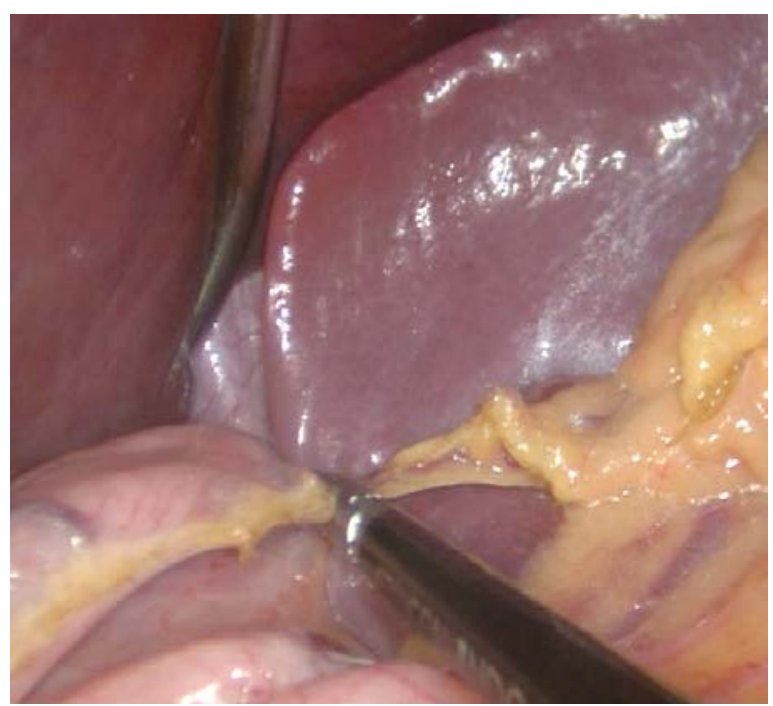

Figure(2): Freeing of the greater curvature.

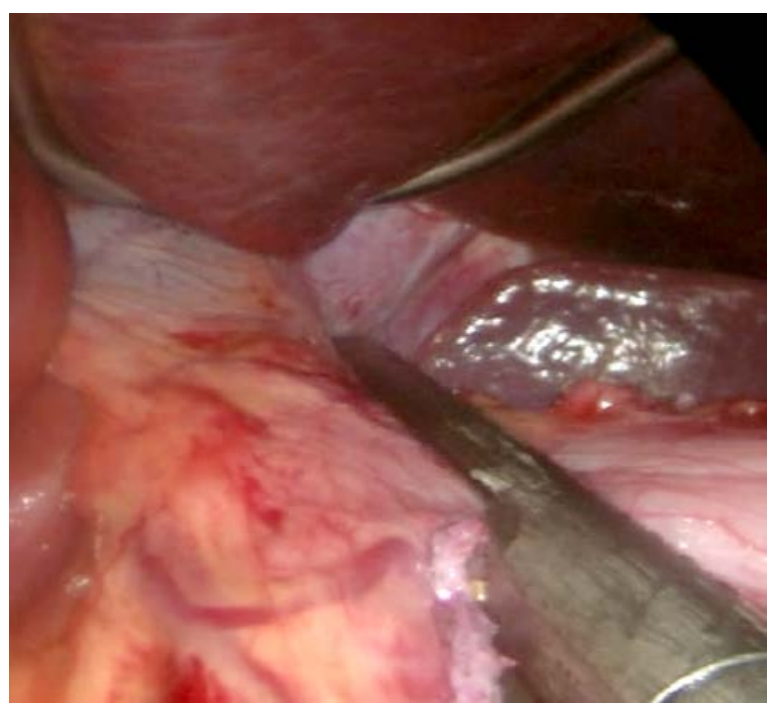

Figure(4): Complete gastric division. 


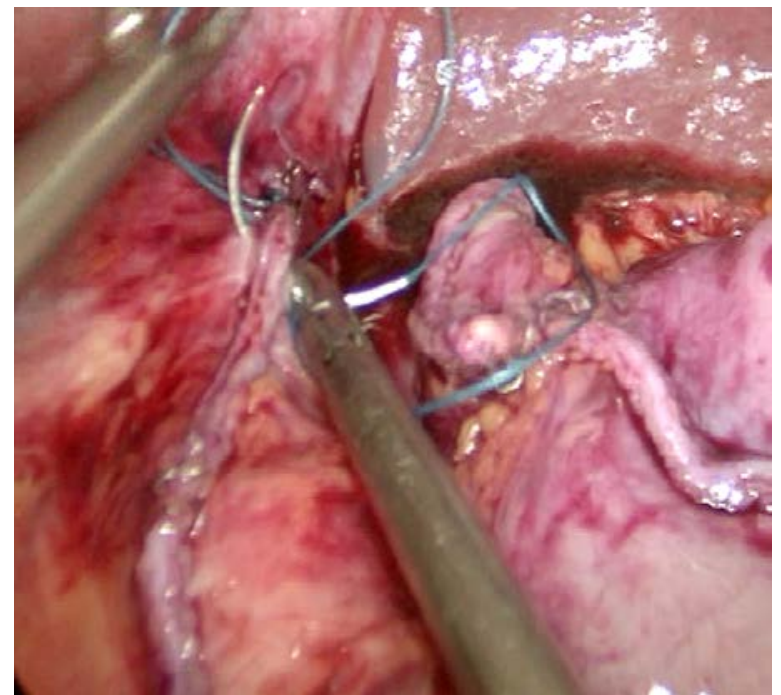

Figure(5): Re-enforcement of division line.

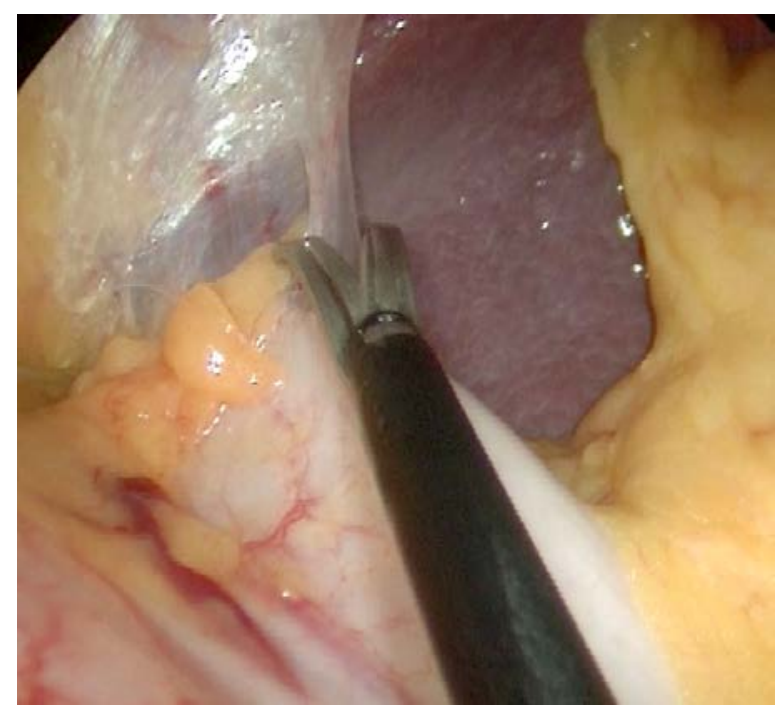

Figure(7): Division of phrenogastric ligament.

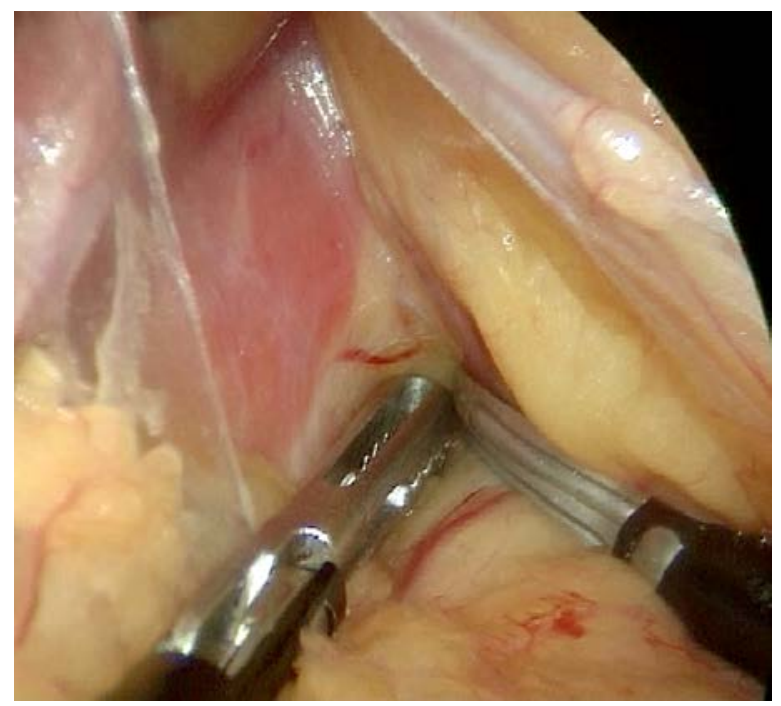

Figure(9): Dissection behind gastro-esophageal junction.

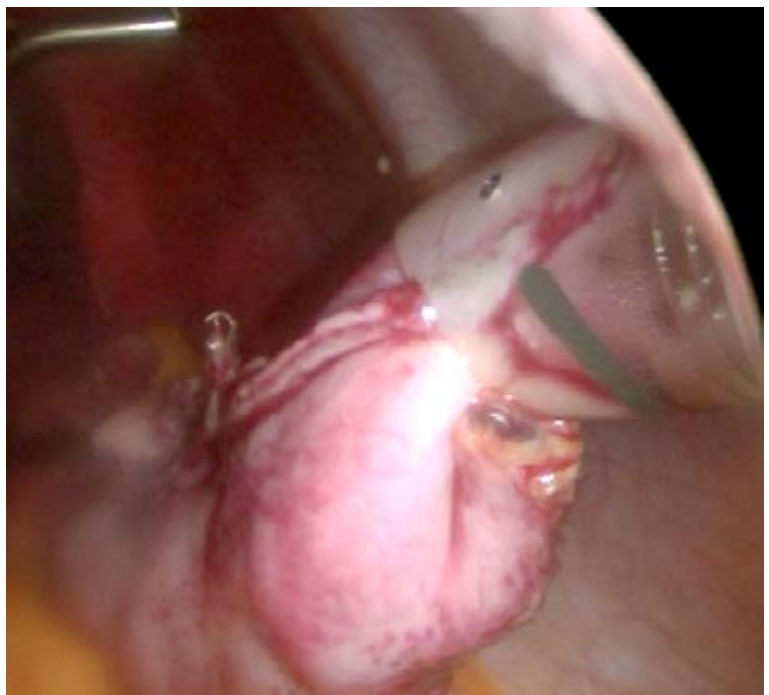

Figure(6): Extraction of resected stomach.

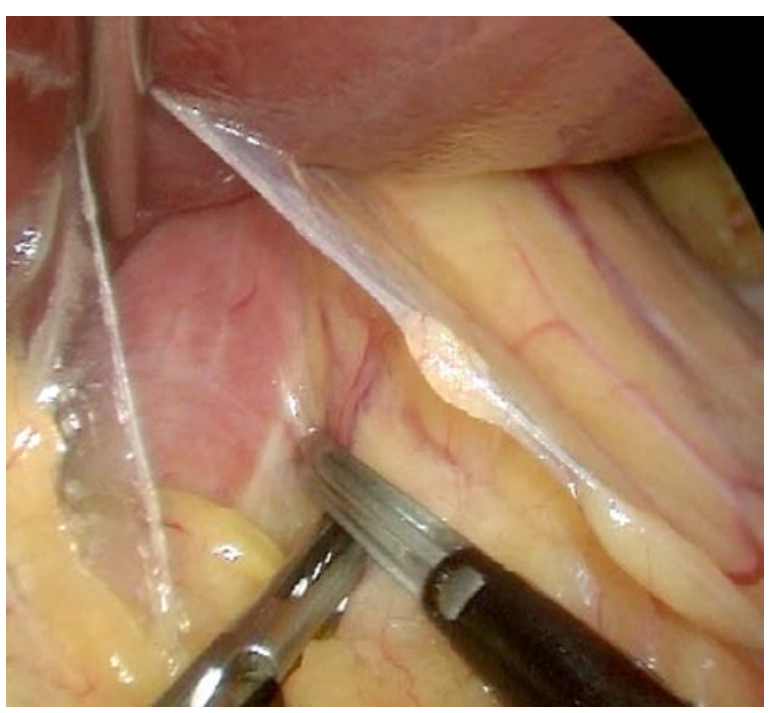

Figure(8): Pars flaccida opened.

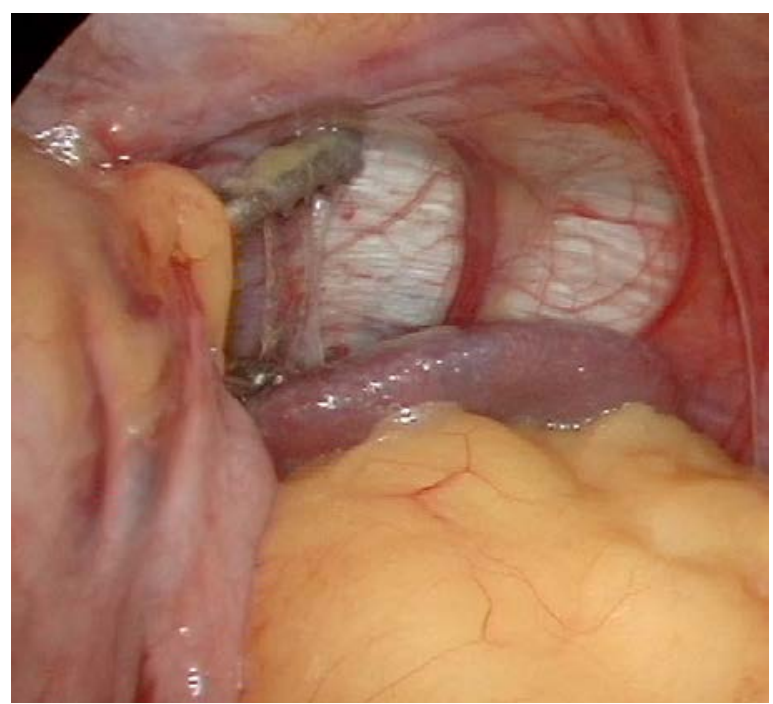

Figure(10): Dissection completed at angle of His. 


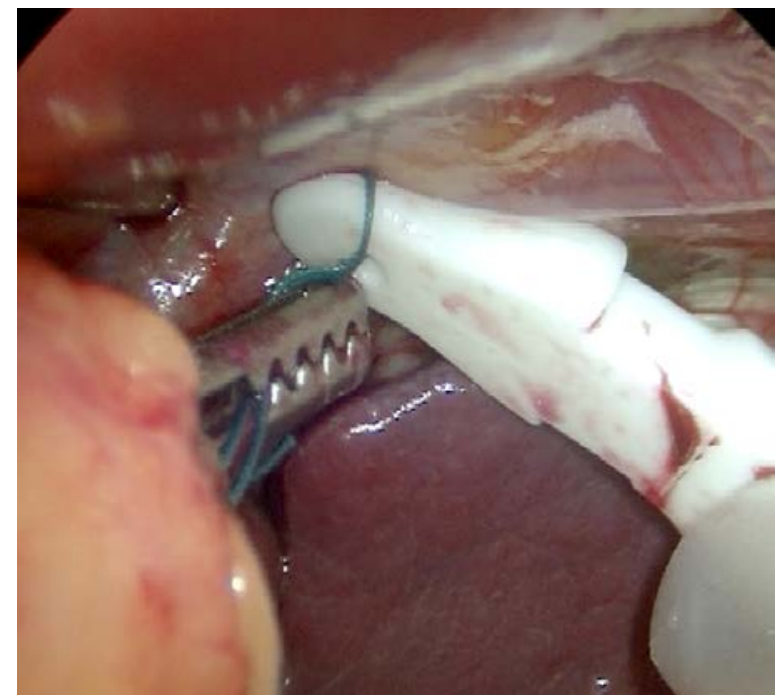

Figure(11): Grasping and pulling of the band.

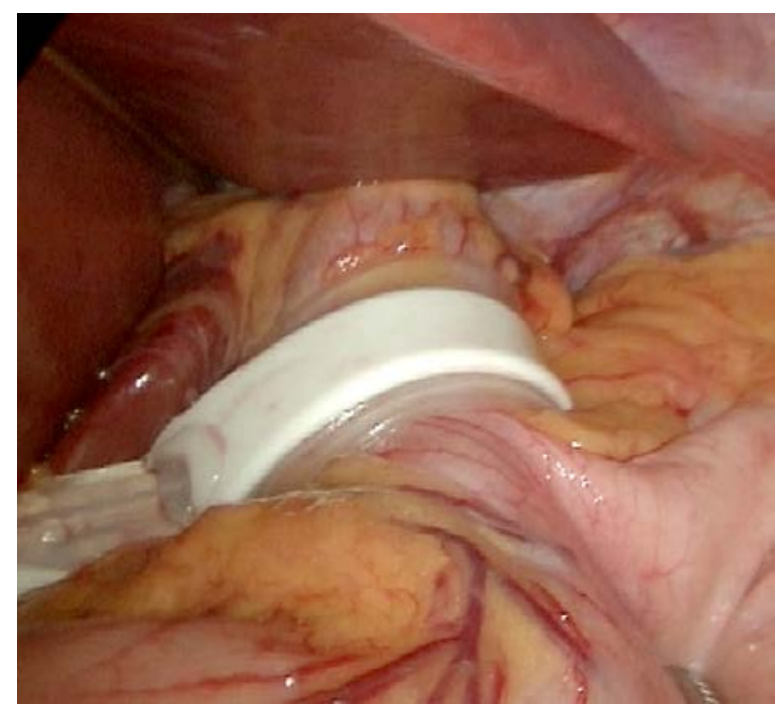

Figure(13): Band encircled around the pouch.

\section{Statistical Analysis:}

All data were analyzed using the Statistical Package of Social Sciences version 11, (SPSS INC Chicago, III) for data processing and analysis.

\section{Results:}

All cases were operated upon between May 2005 and November 2007 when 100 patients (82 females and 18 males), with their ages ranging between 25 and 46 years were randomly assigned into 2 groups for either laparoscopic adjustable gastric banding or laparoscopic sleeve gastrectomy. There were

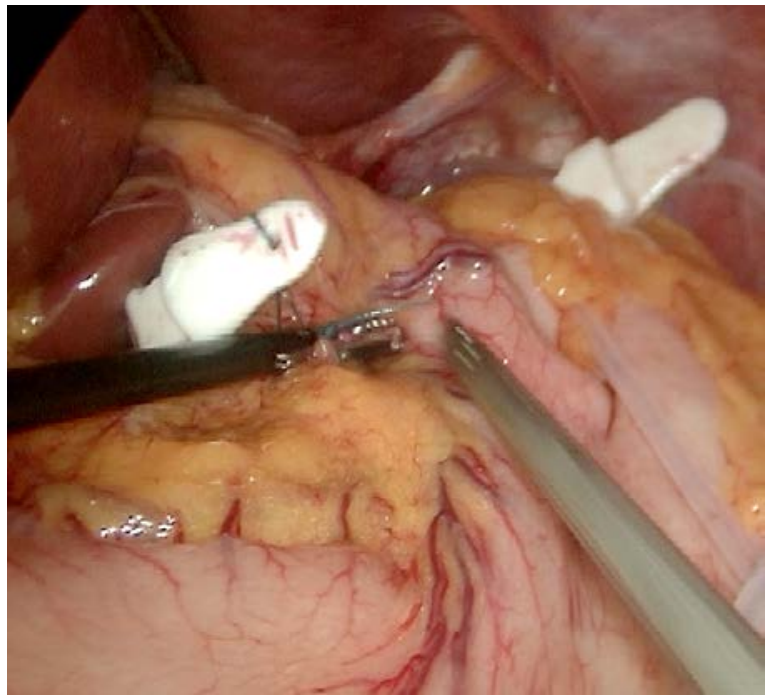

Figure(12): Band in place at retroesophagogastric space.

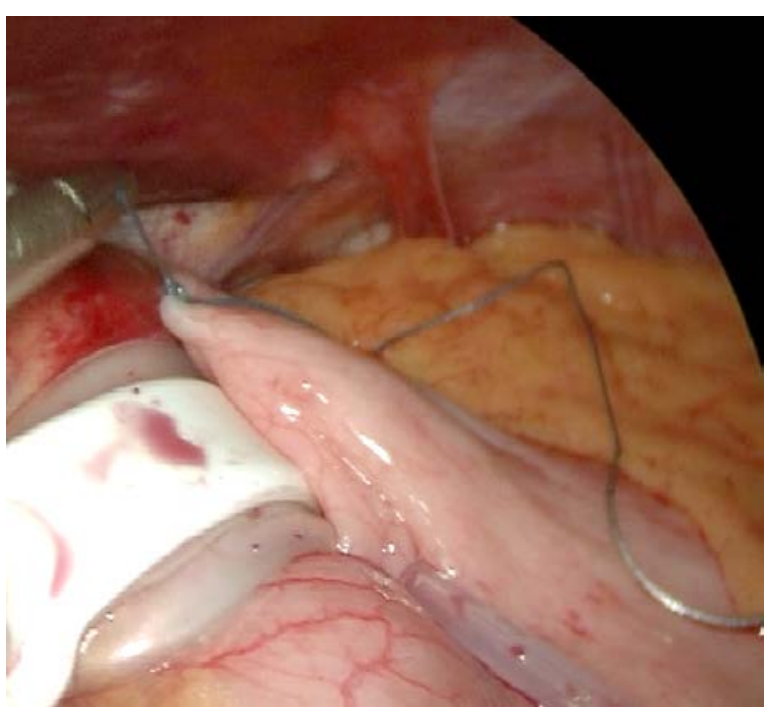

Figure(14): Anterior gastric wall overlapped in front of the band.

no significant differences between both groups regarding age, sex, mean weight and BMI, and pre-operative routine assessment ( $p>0.05)$. Cholecystectomy was done in 5 patients in group 1 and in 4 patients in group 2 due to associated gall bladder stones. There was no mortality in both groups. All procedures were completed by laparoscopy without laparotomy conversion. There was a significant differences between the 2 groups regarding the mean operative time and mean hospital stay $(\mathrm{p}<0.05)$. The patients demographic data and operative results are summarized in Table(1) and Table(2). 
Table (1): Patients demographic data.

\begin{tabular}{|c|c|c|c|c|c|}
\hline Group & No. & $\begin{array}{c}\text { Age } \\
\text { (years) }\end{array}$ & Sex & Wt. (Kg) & $\begin{array}{c}\text { BMI } \\
\left(\mathbf{~ k g} / \mathbf{m}^{\mathbf{2}}\right)\end{array}$ \\
\hline Group 1 & 52 & $36.1 \pm 8$ & $\begin{array}{c}40 \mathrm{~F} \\
12 \mathrm{M}\end{array}$ & $124.5 \pm 27$ & $44.7 \pm 4.5$ \\
\hline Group 2 & 48 & $38.8 \pm 7$ & $42 \mathrm{~F}$ & $128.7 \pm 32$ & $44.2 \pm 5.3$ \\
\hline$p$ value & NS & NS & NS & NS & NS \\
\hline
\end{tabular}

BMI: Body Mass Index, Wt: weight, NS: not significant, S: significant

Table (2): Patients operative results.

\begin{tabular}{|c|c|c|c|c|}
\hline Group & No. & $\begin{array}{c}\text { Associated } \\
\text { Procedure }\end{array}$ & $\begin{array}{c}\text { Mean Operative } \\
\text { Time (minutes) }\end{array}$ & $\begin{array}{c}\text { Mean Hospital } \\
\text { Stay (days) }\end{array}$ \\
\hline Group 1 & 52 & 5 & $87.8 \pm 20.2$ & $2.7 \pm 1.2$ \\
\hline Group 2 & 48 & 4 & $110.2 \pm 36.3$ & $6.2 \pm 2.6$ \\
\hline$p$ value & NS & NS & S & S \\
\hline
\end{tabular}

NS: not significant, S: significant

\section{Follow up Data:}

- After 1 year follow up, there was a statistically significant difference between the two groups regarding the mean BMI and the rate of complications $(\mathrm{p}<0.05)$. The mean BMI was 38.6 in group 1 and 33.2 in group 2 by the end of the 1 st year and the complication rate was $28.8 \%$ in group 1 compared to $18.7 \%$ in group 2 . Three patients $(5.7 \%)$ in group 1 developed GERD symptoms compared to 2 patients $(4.2 \%)$ in group 2 which was not statistically significant $(p>0.05)$. These symptoms were successfully controlled with proton pump inhibitors although temporary band desufflation was required in one patient. There was a significant difference between both groups $(\mathrm{p}<0.05)$ regarding pouch dilatation where 4 patients $(7.6 \%)$ in group 1 and one patient $(2.1 \%)$ in group 2 developed pouch dilatation. In these patients, re-operation was done where band replacement was done in 2 patients, conversion into sleeve gastrectomy was done in one patient; while in the 4th patient, clinical improvement was reported after band desufflation. The other patient with pouch dilatation in group 2 refused any surgical management. No port site herniation was reported in both groups during the 1st year follow up period. Infection at port site developed in 1 patient $(2.1 \%)$ in group 2 which was treated conservatively. Stable line leak was reported in 2 cases $(4.2 \%)$ that were treated surgically. Band erosion was reported in 2 cases $(3.8 \%)$ where re-operation and band removal was done for both of them.

- After 3 years follow up, there was a statistically significant difference between the 2 groups regarding the mean BMI $(\mathrm{p}<0.05)$ being 36.7 for patients in group 1 and 31.2 in group 2. There was no significant difference between the two groups regarding the rate of complications ( $p>0.05)$. Six patients $(12.5 \%)$ in group 2 developed GERD where the medical treatment was effective in 4 of them. In the remaining 2 patients, re-operation and conversion to Roux-en-Y gastric bypass was done due to persistence of GERD symptoms despite the medical treatment. Four patients $(8.3 \%)$ in group 2 acquired pouch dilatation. Re-operation and conversion to Roux-en-Y gastric bypass was done to 2 of them and the other remaining 2 patients refused any surgical correction. Band erosion occurred in one more patient that required surgical removal. 
Herniation at the right hypochondral port site developed in one patient $(2.1 \%)$ in group 2 that required surgical repair. Insufficient weight loss was present in 2 patients $(3.8 \%)$ in group 1 and in 2 patients (4.2\%) in group 2 which was not statistically significant ( $p>0.05)$. The post-operative results and complications after 1 and 3 years are summarized in Table(3).

Table (3): Post-operative results and complications.

\begin{tabular}{|l|c|c|c|c|c|c|}
\hline \multirow{2}{*}{$\begin{array}{c}\text { Long term results } \\
\text { and complications }\end{array}$} & \multicolumn{4}{|c|}{ 1 year } & \multicolumn{3}{c|}{ years } \\
\cline { 2 - 7 } & Group 1 & Group 2 & $\boldsymbol{p}$ value & Group 1 & Group 2 & p value \\
\hline BMI & $38.6 \pm 2.3$ & $33.2 \pm 3.4$ & S & $36.7 \pm 2.9$ & $31.2 \pm 4.1$ & S \\
\hline Rate of complications \% & $28.8 \%$ & $18.7 \%$ & S & $36.5 \%$ & $39.6 \%$ & NS \\
\hline Mortality & - & - & - & - & - & - \\
\hline GERD & $3(5.7 \%)$ & $2(4.2 \%)$ & NS & $4(7.6 \%)$ & $6(12.5 \%)$ & NS \\
\hline Stable line leak & - & $2(4.2 \%)$ & NS & - & $2(4.2 \%)$ & NS \\
\hline Pouch dilatation & $4(7.6 \%)$ & $1(2.1 \%)$ & S & $4(7.6 \%)$ & $4(8.3 \%)$ & NS \\
\hline Band erosion & $2(3.8 \%)$ & - & NS & $3(5.7 \%)$ & - & NS \\
\hline Port site infection & - & $1(2.1 \%)$ & NS & - & $1(2.1 \%)$ & NS \\
\hline Port site herniation & - & - & - & - & $1(2.1 \%)$ & NS \\
\hline Food intolerance & $2(3.8 \%)$ & $2(4.2 \%)$ & NS & $4(7.6 \%)$ & $3(6.3 \%)$ & NS \\
\hline Non-compliance & $2(3.8 \%)$ & - & NS & $2(3.8 \%)$ & - & NS \\
\hline Inadequate wt. loss & $2(3.8 \%)$ & $1(2.1 \%)$ & NS & $2(3.8 \%)$ & $2(4.2 \%)$ & NS \\
\hline Re-operation & $5(9.6 \%)$ & $2(4.2 \%)$ & S & $6(11.5 \%)$ & $5(10.4 \%)$ & NS \\
\hline
\end{tabular}

NS: not significant, S: significant, GERD: Gastroesophageal Reflux Disease, BMI: Body Mass Index

\section{Discussion:}

In recent years, the minimally invasive approach has become the preferred technique for bariatric surgery. All bariatric procedures are now routinely performed laparoscopically. Explanations for this trend include several advantages related to less postoperative discomfort and reduced surgical risk for obese patients. ${ }^{10}$ Beginning with gastric banding and vertical band gastroplasty, followed by gastric bypass, gastric sleeve, duodenal switch, biliopancreatic diversion, the laparoscopic approach has gradually replaced the corresponding traditional open operations. ${ }^{11}$ In Europe, the tumultuous development of gastric banding was based on the simplicity and feasibility of the technique with an excellent immediate postoperative course. ${ }^{12}$ However, there is limited availability of midterm and long-term results. ${ }^{12,13}$ Recently, some concern has arisen regarding the efficacy of restrictive gastric procedures as therapy for morbid obesity ${ }^{12,14}$ although only a few studies on sleeve gastrectomy for morbid obesity have been published so far. ${ }^{15}$ Despite the prevalent use of bariatric surgery during the past years, there is no controlled trial comparing laparoscopic banding versus laparoscopic sleeve gastrectomy could be found. In the present study, we compared laparoscopic adjustable gastric banding with the sleeve gastrectomy. Both procedures were safe without mortality. The mean operative time and hospital stay were significantly shorter with gastric banding. Shorter operative time and a smoother postoperative course led to shorter mean length of hospitalization in the band group which correlates with other studies. ${ }^{14,15}$ There was statistically significant difference between both groups regarding the early reoperation rate being higher in band group during the 1 st year either due to complications or failure to get the required weight loss. This correlates with some studies where major re-operations were required in $21.7 \%$ of all patients with gastric banding 16 and does not correlate with others where the need for early reoperation rate was attributed to few cases. ${ }^{17,18}$ Pouch dilatation was reported in both groups. Although it was significantly 
higher in band group after one year follow up, it became insignificant after three years where equal patients in both groups developed pouch dilatation. Pouch dilatation as well as other complications including band erosions and band slippage were reported in one study done over 100 patients with gastric banding where one third $(33.1 \%)$ of their patients developed late complications such as band erosion, pouch dilation, band slippage, and catheter and port related problems. ${ }^{16,18}$ Band erosion was a great problem in 3 patients of our study; a complication reported by several authors at a rate of $1 \%$ and $3 \% 19$ although some other studies did not experience band erosion. ${ }^{20}$ Stable line leak was reported in $4.2 \%$ of our patients, a complication reported by other studies that needed surgical correction. ${ }^{21-23}$ The rate of complications was significantly higher in band group during the 1 st year of follow-up. After 3 years, there was no significant difference between complication rates in both groups. The vast majority of scientific reports on laparoscopic gastric banding have a short follow-up which limits their usefulness and scientific value, as longterm complication and re-operation rates are of utmost importance. However, there have been several publications on laparoscopic gastric bands that report a long-term follow up. Suter and colleagues summarized their prospectively collected results on 317 patients undergoing laparoscopic banding. Long-term follow up was excellent ( $88.2 \%$ at 5 years). One third $(33.1 \%)$ of their patients developed late complications such as band erosion, pouch dilation, band slippage, and port related problems. Major re-operations were required in $21.7 \%$ of all patients and the failure rate consistently increased from $23.8 \%$ at 3 years to $31.5 \%$ at 5 years, up to $36.9 \%$ at 7 years. The 7-year success rate (defined as excessive weight loss of more than 50\%) was extremely low (43\%). Based on these concerning and disappointing results, the authors concluded that "laparoscopic banding should no longer be considered as the procedure of choice for obesity".24 In terms of weight loss, the resulting BMI was significantly lower in sleeve group with satisfactory weight loss in most of the patients at the 1 and 3 year intervals. Different weight loss outcomes following laparoscopic gastric band and sleeve gastrectomy are reported in the literature. Several authors report results nearly similar to our study $25-27$ with a resulting BMI at 3 years of 33 to $36 \mathrm{~kg} / \mathrm{m}^{2}$. On the other hand, some series report better outcomes 28,29 with a resulting BMI around $30 \mathrm{~kg} / \mathrm{m}^{2}$. The main difference of these studies seems to be the selection of the patients, in the fact that restrictive gastric surgery is found to be more efficient in the mildly obese rather than the superobese patient population. ${ }^{29}$ In studies with the best results, the preoperative average BMI was 42 to $43 \mathrm{~kg} / \mathrm{m}^{2}$. In studies with the poorest results, initial BMI was 44 to $46 \mathrm{~kg} / \mathrm{m}^{2} .{ }^{30-32}$ There are numerous other investigations that report rates of gastric band removal up to $60 \% .{ }^{33-36}$ The scientific evidence on the high rates of re-operation after laparoscopic gastric banding is alarming. An increasing number of reports describe the conversion from gastric banding to other bariatric procedures including laparoscopic VBG, sleeve resection, and duodenal switch. ${ }^{37,38}$ Proponents of the laparoscopic gastric band argue that improvements in the surgical technique (e.g. pars flaccida technique) and the quality and design of bands have considerably reduced the number of complications. While this is true for band slippage, 39 the rate of long-term complications, including band removals, remain high. ${ }^{40,41}$ Therefore, in conclusion, the data from our trial showed that in carefully selected patients, nonbinge and nonsweet eaters with an initial BMI limited to 40 to $49 \mathrm{~kg} / \mathrm{m}^{2}$, restrictive surgery can give good results. Sleeve gastrectomy is significantly more effective than gastric banding in terms of late complications, late reoperations, and long-term results on weight loss.

\section{References:}

1- Kopelman PG: Obesity as a medical problem. Nature 2000; 404: 635-643.

2- Buchwald H, Avidor Y, Braunwald E, et al: Bariatric surgery: A systematic review and meta-analysis. JAMA 2004; 292: 17241737.

3- Maggard M, Shugarman L, Suttorp M, et al: Meta-analysis: Surgical treatment of 
obesity. Ann Intern Med 2005; 142: $547-$ 559.

4- Buchwald H, Williams S: Bariatric surgery worldwide. Obes Surg 2004; 14:1157-1164.

5- Rivas H, Martinez J, Delgado S, et al: Current attitudes to the laparoscopic bariatric operations among European surgeons. Obes Surg 2004; 14(9): 12471251.

6- Rosenthal R, Szomstein S, Kennedy C, et al: Laparoscopic surgery for morbid obesity: 1, 001 consecutive bariatric operations performed at The Bariatric Institute, Cleveland Clinic, Florida. Obes Surg 2006; 16(2): 119-124.

7- Morino M, Toppino M, Garrone C, et al: Laparoscopic adjustable silicone gastric banding for the treatment of morbid obesity. Br J Surg 1994; 81(8): 1169-1170.

8- Pratt G, Learn C, Hughes G, et al: Demographics and outcomes at American Society for Metabolic and Bariatric Surgery Centers of Excellence. Surg Endosc 2009; 23: 795-799.

9- Silecchia G, Bacci V, Bacci S, et al: Reoperation after laparoscopic adjustable gastric banding: analysis of a cohort of 500 patients with long-term follow-up. Surg Obes Relat Dis 2008; 4: 430-436.

10-O'Brien P, McPhail T, Chaston T, et al: Systematic review of medium-term weight loss after bariatric operations. Obes Surg 2006; 16: 1032-1040.

11-Schauer P, Ikramuddin S: Laparoscopic surgery for morbid obesity. Surg Clin North Am 2001; 81: 1145-1179.

12-Favretti F, Cadicre G, Segato G, et al: Laparoscopic banding: Selection and technique in 830 patients. Obes Surg 2002; 12: 385-390.

13-Mognol P, Marmuse J: Laparoscopic gastric bypass versus laparoscopic adjustable gastric banding in the super-obese: A comparative study of 290 patients. Obes Surg 2005; 15: 76-81.

14-Tice J, Karliner L, Walsh J, et al: Gastric banding or bypass? A systematic review comparing the two most popular bariatric procedures. Am J Med 2008; 121: 885-893.

15-Baltasar A, Serra C, Perez N, et al: Laparoscopic sleeve gastrectomy: A multi- purpose bariatric operation. Obes Surg 2005; 15: 1124-1128.

16-Tucker O, Sucandy I, Szomstein S, et al: Revisional surgery after failed laparoscopic adjustable gastric banding. Surg Obes Relat Dis 2008; 4: 740-747.

17-Himpens J, Dapri G, Cadiere G: A prospective randomized study between laparoscopic gastric banding and laparoscopic isolated sleeve gastrectomy: Results after 1 and 3 years. Obes Surg 2006; 16(11): 1450-1456.

18-Silecchia G, Boru C, Pecchia A, et al: Effectiveness of laparoscopic sleeve gastrectomy (first stage of biliopancreatic diversion with duodenal switch) on comorbidities in super-obese high-risk patients. Obes Surg 2006; 16(9): 11381144.

19-DeMaria E, Surgerman H, Meador J, et al: High failure rate after laparoscopic adjustable silicone gastric banding for treatment of morbid obesity. Ann Surg 2001; 233: 809-818.

20-Mario M, Mauro T, Gisella B, et al: Laparoscopic adjustable silicone gastric banding versus vertical banded gastroplasty in morbidly obese patients: A prospective randomized controlled clinical trial. Ann Surg 2003; 238: 835-842.

21-Roa P, Pinto D, Cho M, et al: Laparoscopic sleeve gastrectomy as treatment for morbid obesity: Technique and short-term outcome. Obes Surg 2006; 16: 1323-1326.

22-Baker R, Foote J, Kemmeter P, et al: The science of stapling and leaks. Obes Surg 2004; 14: 1290-1298.

23-Hamoui N, Anthone G and Kaufman H: Sleeve gastrectomy in the high-risk patient. Obes Surg 2006; 16(11): 1445-1449.

24-Suter M, Calmes J, Paroz A, et al: A 10year experience with laparoscopic gastric banding for morbid obesity: High longterm complication and failure rates. Obes Surg 2006; 16(7): 829-835.

25-DeMaria E, Surgerman H, Meador J, et al: High failure rate after laparoscopic adjustable silicone gastric banding for treatment of morbid obesity. Ann Surg 2001; 233: 809-818. 
26-Moon S, Kim W, Oh J: Results of laparoscopic sleeve gastrectomy (LSG) at 1 year in morbidly obese Korean patients. Obes Surg 2005; 15: 1469-1475.

27-Cottam D, Qureshi F, Mattar S, et al: Laparoscopic sleeve gastrectomy as an initial weight-loss procedure for high-risk patients with morbid obesity. Surg Endosc 2006; 20(6): 859-863.

28-Szold A, Abu-Abeid S: Laparoscopic adjustable silicone gastric banding for morbid obesity: Results and complications in 715 patients. Surg Endosc 2002; 16: 230-233.

29-Weitner R, Bockhorn H, Rosenthal R, et al: A prospective randomized trial of different laparoscopic gastric banding techniques for morbid obesity. Surg Endosc 2001; 15: 63-68.

30-Bueter M, Maroske J, Thalheimer A, et al: Short- and long-term results of laparoscopic gastric banding for morbid obesity. Langenbecks Arch Surg 2008; 393:199205.

31-Biagini J and Karam L: Ten years experience with laparoscopic adjustable gastric banding. Obes Surg 2008; 18:573577.

32-Ponce J, Paynter S and Fromm R: Laparoscopic adjustable gastric banding: 1,014 consecutive cases. J Am Coll Surg 2005; 201: 529-535.

33-Bueter M, Thalheimer A, Lager C, et al: Who benefits from gastric banding? Obes Surg 2007; 17:1608-1613.

34-Weber M, Muller M, Bucher T, et al: Laparoscopic gastric bypass is superior to laparoscopic gastric banding for treatment of morbid obesity. Ann Surg 2004; 240: 975-982.

35-Lanthaler M, Sieb M, Strasser S, et al: Disappointing mid-term results after laparoscopic gastric banding in young patients. Surg Obes Relat Dis 2009; 5(2): 218-23.

36-Riele W, Dejong J, Vogten J, et al: Sustained weight loss 2 years after laparoscopic adjustable gastric banding for morbid obesity. Ned Tijdschr Geneeskd 2007; 151: 1130-35.

37-Allen J, Coleman M, Fielding G: Lessons learned from laparoscopic gastric banding for morbid obesity. Am J Surg 2001; 182: 10-14.

38-Sjostrom L, Narbro K, Sjostrom C, et al: Effects of bariatric surgery on mortality in Swedish obese subjects. $N$ Engl J Med 2007; 357: 741-752.

39-Baltasar A, Serra C, Perez N, et al: Laparoscopic sleeve gastrectomy: A multipurpose bariatric operation. Obes Surg 2005; 15(8): 1124-1128.

40-Fielding G and Duncombe J: Clinical and radiological follow-up of laparoscopic adjustable gastric bands, 1998 and 2000: A comparison of two techniques. Obes Surg 2005; 15: 634-640.

41-Wolnerhanssen B, Peters T, Kern B, et al: Predictors of outcome in treatment of morbid obesity by laparoscopic adjustable gastric banding: Results of a prospective study of 380 patients. Surg Obes Relat Dis 2008; 4: 500-506. 